OPEN ACCESS

Edited by:

Ren-You Gan,

University of Hong Kong, Hong Kong

Reviewed by:

Sui Kiat Chang,

International Medical University,

Malaysia

Tangbin Zou,

Guangdong Medical College, China

Yun Ping Neo,

Taylors University, Malaysia

${ }^{*}$ Correspondence:

Alam Zeb

azebuom@gmail.com

Specialty section

This article was submitted to

Food Chemistry,

a section of the journal

Frontiers in Chemistry

Received: 28 February 2017

Accepted: 10 April 2017

Published: 27 April 2017

Citation:

Zeb A and Ullah F (2017) Reversed

Phase HPLC-DAD Profiling of

Carotenoids, Chlorophylls and Phenolic Compounds in Adiantum

capillus-veneris Leaves.

Front. Chem. 5:29

doi: 10.3389/fchem.2017.00029

\section{Reversed Phase HPLC-DAD Profiling of Carotenoids, Chlorophylls and Phenolic Compounds in Adiantum capillus-veneris Leaves}

\author{
Alam Zeb * and Fareed Ullah \\ Laboratory of Biochemistry, Department of Biotechnology, Faculty of Biological Sciences, University of Malakand, Chakdara, \\ Pakistan
}

Adiantum capillus-veneris is important endangered fern species with several medicinal properties. In this study, the leaves samples were extracted and separated using reversed phase HPLC with DAD for carotenoids, chlorophylls and phenolic compounds. Separation of carotenoids and chlorophylls were carried out using a tertiary gradient system of water, MTBE and methanol-water, while a binary gradient system of methanol-water-acetic acid was used for phenolic profiling. Results revealed eight carotenoids, four pheophytins, and two chlorophylls. Lutein $(806.0 \mu \mathrm{g} / \mathrm{g})$, chlorophyll $b^{\prime}(410.0 \mu \mathrm{g} / \mathrm{g})$, chlorophyll a $(162.4 \mu \mathrm{g} / \mathrm{g}), 9^{\prime}$-Z-neoxanthin $(142.8 \mu \mathrm{g} / \mathrm{g})$ and all-E-violaxanthin $(82.2 \mu \mathrm{g} / \mathrm{g})$ were present in higher amounts. The relatively high amounts of lutein may be one of the key indicator of beneficial antioxidant properties. The phenolic profile revealed a total of 13 compounds, namely 4-hydroxybenzoic acid, chlorogenic acid, caftaric acid, kaempferol glycosides, p-coumaric acid, rosmarinic acid, 5-caffeoylquinic acid, and quercetin glycosides. Kaempferol-3-sophorotrioside (58.7 mg/g), chlorogenic acid (28.5 mg/g), 5-O-caffeoylquinic acid (18.7 mg/g), coumaric acid $(11.2 \mathrm{mg} / \mathrm{g})$, and its derivative $(33.1 \mathrm{mg} / \mathrm{g})$ were present in high amounts. These results suggest that the reversed phase HPLC profiling of Adiantum leaves provides a better understanding in to the actual composition of bioactive compounds, which may be responsible for the potential medicinal properties. Adiantum leaves rich in important bioactive phytochemicals can be used as a possible source of nutraceuticals or as a functional food ingredient.

Keywords: Adiantum, carotenoids, chlorophylls, phenolic compounds, reversed phase HPLC

\section{INTRODUCTION}

Adiantum capillus-veneris also known as Venus hair fern is commonly grown species from the garden to the humid coniferous forest. It is a small plant which grows up to $30 \mathrm{~cm}$ height and extensively propagated. Adiantum capillus-veneris is used as traditional medicine for curing various diseases (Al-Snafi, 2015). The plant is used in Ayurvedic system of medicine for certain health conditions such as cold, tumors of the spleen and liver, skin diseases, bronchitis, and inflammation (Singh et al., 2008). The extracts of the leaves have strong anti-microbial activities (Singh et al., 2008; Reinaldo et al., 2015). The hydro-alcoholic extract of leaves has strong anti-urolithic properties 
that are usually claimed (Ahmed et al., 2013). Among the medicinal properties of Adiantum leaves, anti-inflammatory and analgesic effects (Haider et al., 2011) are driving the attention of phytochemists to look for other chemical constituents that might be of the potential biological interest. For example, Adiantum leaves extract contains high level of flavonoids were a good source of antioxidants (Jiang et al., 2011). Reddy et al. (2001) isolated new terpenoids that was 22,29-epoxy-30norhopan-13-ol from the Adiantum leaves with strong antibacterial activity. Phytochemical analyses of Adiantum leaves revealed the presence of flavonoids, alkaloids, tannins, saponins, glycosides, steroids, and terpenoids with anti-bacterial and antifungal activity (Ishaq et al., 2014). Limited studies showed the phenolic profile of the Adiantum leaves. For example, Yuan et al. (2012) identified seven bioactive compounds, containing 3-coumaroylquinic acid, kaempferol-3-glucosides as major phenolic compounds. Similarly, quercetin, quercetin-3glucoside and quercetin-3-rutinoside were then identified in the leaves and extracts were found helpful against inflammation and hypoglycemia (Ibraheim et al., 2011).

Reversed phase liquid chromatography is extensively used chromatographic technique for profiling of bioactive phytochemicals such as phenolic compounds and carotenoids in plants (Chiste and Mercadante, 2012). Phenolic compounds are usually stable during extraction and analysis, while carotenoids are prone to oxidation and thus special attention are required for correct measurement (Luterotti and Kljak, 2010). Carotenoids obtained from plants play a significant biological role in plant or in human. Lutein, zeaxanthin, and other carotenoids are important for proper visual function (Hammond and Fletcher, 2012). The anti-cancer properties of carotenoids have been widely studied (Soares Nda et al., 2015). Thus, it is imperative to find out the possible resources of these bioactive phytochemicals especially among the underutilized plants.

Due to the lack of information about the carotenoids, chlorophylls, and phenolic profile of Adiantum leaves, reversed phase HPLC would provide better insight in to the important phytochemicals. This study revealed for the first time, the reversed phase HPLC-DAD profiling of carotenoids and chlorophylls as well as phenolic compounds present in the Adiantum capillus-veneris L. leaves from Pakistan with the aim to determine its nutritional importance of this underutilized plant for future uses.

\section{MATERIALS AND METHODS}

\section{Materials}

Methanol (Pubchem CID 887), ethanol (Pubchem CID 702), p-hydroxybenzoic acid (Pubchem CID 135), 3-O-caffeoylquinic acid (Pubchem CID 1794427), 5-O-caffeoylquinic acid (Pubchem CID 5280623), 2-caffeoyl tartaric acid (Pubchem CID 6440397), chlorophyll a (Pubchem CID 6477652), all-E-violaxanthin (Pubchem CID 448438), and lutein (Pubchem CID 5281243) were from Sigma-Aldrich (Germany). p-Coumaric acid (Pubchem CID 637542) and MTBE (Pubchem CID 104324) were from Daejung (South Korea). Acetone was purchased from Merck (Germany).

\section{Sample Collection}

Samples of Adiantum capillus-veneris leaves were collected from the Local forest in Ghalegay District Swat, Pakistan. The latitude, longitude and altitude of the sampling area were $34.699153^{\circ}$, $72.263026^{\circ}$ and $2,450 \mathrm{~m}$ with large flora (Hussain et al., 2006). The average temperature of the collection site was $32.5^{\circ} \mathrm{C}$. Leaves samples were removed, washed with water, and grinded in Laboratory blender. The fresh grinded sample was used for the extraction on the same day of collection.

\section{Sample Extractions}

For the analyses of phenolic compounds, samples (1 g each) in triplicates were mixed with methanol-water (90:10, v/v) and vigorously shaken for $1 \mathrm{~h}$ at $40^{\circ} \mathrm{C}$ in water bath. The extraction was repeated thrice. The samples were then filtered using Whatman ${ }^{\circledR}$ general purpose filter paper (diameter $90 \mathrm{~mm}$, Sigma-Aldrich, Germany) and centrifuged at 4,000 rpm for $30 \mathrm{~min}$. The filtrate was concentrated using vacuum evaporation and filtered again using Agilent PTFE $0.45 \mu \mathrm{m}$ filter paper (Agilent Technologies, Waldbronn, Germany) and transferred directly in to HPLC vials $(2 \mathrm{~mL})$.

For carotenoids and chlorophyll extractions, the method of Kimura and Rodriguez-Amaya (2002) was adopted with some modifications. In brief, $1 \mathrm{~g}$ sample was mixed with $10 \mathrm{~mL}$ of ice cold acetone and vortexed for $30 \mathrm{~min}$. Ice cold ethanol $(5 \mathrm{~mL})$ was added to it and again vortexed again for $30 \mathrm{~min}$. The samples were filtered and the extractions were repeated thrice or until discoloration of the substrate occurred. The extracted samples were concentrated in vacuum at $40^{\circ} \mathrm{C}$. The residue was dissolved in HPLC eluent and filtered using Agilent syringe filters (Agilent Technologies, Waldbronn, Germany) to HPLC vials.

\section{HPLC Analyses of Carotenoids and Chlorophylls}

Carotenoids and chlorophylls were determined using a reversed phase HPLC method (Zeb, 2017). The separation was achieved with Agilent rapid resolution column (Agilent Zorbax Eclipse C18, Agilent Technologies, Germany, $4.6 \times 100 \mathrm{~mm}, 3.5 \mu \mathrm{m}$ ). The tertiary gradient system consists of methanol: deionized water $(92: 8, \mathrm{v} / \mathrm{v})$ with $10 \mathrm{mM}$ ammonium acetate as solvent $\mathrm{A}$, solvent $\mathrm{B}$ was deionized water containing $0.01 \mathrm{mM}$ of ammonium acetate and solvent $\mathrm{C}$ was MTBE (100\%) at the flow rate of $1 \mathrm{~mL} / \mathrm{min}$. The gradient program was started with $80: 18: 2 \%$ each of A:B:C solvents. At 3 min the ratio of the solvents was $80: 12: 8$ and $65: 5: 30 \%$ of A:B:C respectively in $25 \mathrm{~min}$. The gradient reached $60: 0: 40$ of $\mathrm{A}: \mathrm{B}: \mathrm{C}$ at 40 min with post gradient elution of $10 \mathrm{~min}$ for recovery of the initial solvent system. The spectra were recorded in the range of $200-750 \mathrm{~nm}$ and the chromatograms were obtained at 450 and $650 \mathrm{~nm}$. The identification of carotenoids and chlorophylls were based on either the available standards (All- $E$-violaxanthin, chlorophyll $a$ and lutein), their retention times, or by comparing the absorption spectra reported in the literature. Only those compounds were used for quantification, where the peak purity was higher than $95 \%$. The quantification of the pigment where standard was not available, the calibration curve of available standard with similar 
chromatographic response factor was used. The LOD \& LOQ of the method were reported earlier (Zeb, 2017).

The amount of each carotenoid was calculated on fresh weight basis using the following formula:

$$
\text { Carotenoid }\left(\frac{\mu g}{g}\right)=\left(C x\left(\frac{\mu g}{m L}\right) \times V(m L) \times D\right) / W t
$$

Where $C x$ is the concentration of each carotenoid calculated from the standard calibration curve in $\mu \mathrm{g} / m L, V$ is the volume of the extraction in $m L, D$ is any dilution factor, while Wt is weight in gram of fresh sample.

\section{HPLC Analyses of Phenolic Compounds}

Phenolic compounds were determined using the HPLC-DAD system described above with same column specifications,

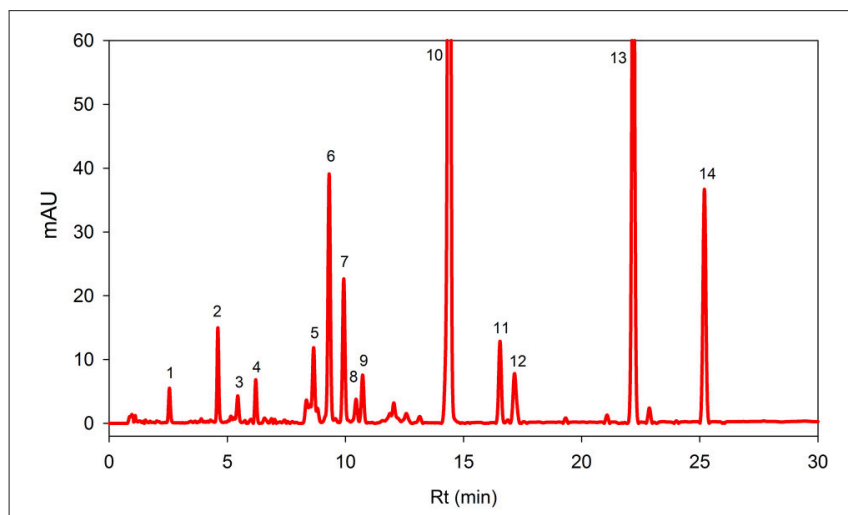

FIGURE 1 | Reversed phase HPLC-DAD profile of carotenoids and chlorophylls in the Adiantum leaves at $450 \mathrm{~nm}$. Each peak represents individual identified compounds with details given in Table 1. but specifically optimized and maintained for plant phenolic analyses. The gradient system consists of solvent A with a composition of methanol-acetic acid-deionized water (10-2$88, \mathrm{v} / \mathrm{v}$ ) and solvent $\mathrm{B}$ with a composition of methanol-acetic acid-deionized water (90-2-8, v/v). The gradient elution was started with A (100\%), in $5 \mathrm{~min} 85 \% \mathrm{~A}$, reaching $50 \% \mathrm{~A}$ at $20 \mathrm{~min}, 30 \% \mathrm{~A}$ at $25 \mathrm{~min}$, and $100 \% \mathrm{~B}$ from 30 to $40 \mathrm{~min}$ as reported in a recent work (Zeb, 2015). Three wavelengths, i.e., 280,320 , and $360 \mathrm{~nm}$ were used for the detection of phenolic compounds. The spectra were recorded from 200 to $600 \mathrm{~nm}$. The identification was carried out using available standards, retention times, and UV spectra or comparison with literature. The quantification of identified compounds was based on the peak area against the standard calibration curves prepared from $\mathrm{p}$ hydroxybenzoic acid, chlorogenic acid, caftaric acid, p-coumaric acid, and quercetin.

The amount of each phenolic compound was calculated on fresh weight basis using the following formula:

Phenolic compound $\left(\frac{m g}{g}\right)=\left(A x\left(\frac{m g}{m L}\right) \times V(m L) \times D\right) / W t$

Where $A x$ is the concentration of each phenolic compound calculated from the standard calibration curve in $\mathrm{mg} / \mathrm{mL}, V$ is the volume of the extraction in $m L, D$ is any dilution factor, while $W t$ is weight in gram of fresh sample. In case where standard phenolic compound was not available, the calibration curve of available standard with equal chromatographic response factor was used.

\section{Data Analyses}

All analyses were carried out in triplicate or otherwise mentioned. Data from the chromatograms were transferred as CSV file to Sigma-Plot (version 12.3) to obtain better resolution of the chromatograms.

TABLE 1 | Carotenoids and chlorophylls profiling and quantification in Adiantum leaves.

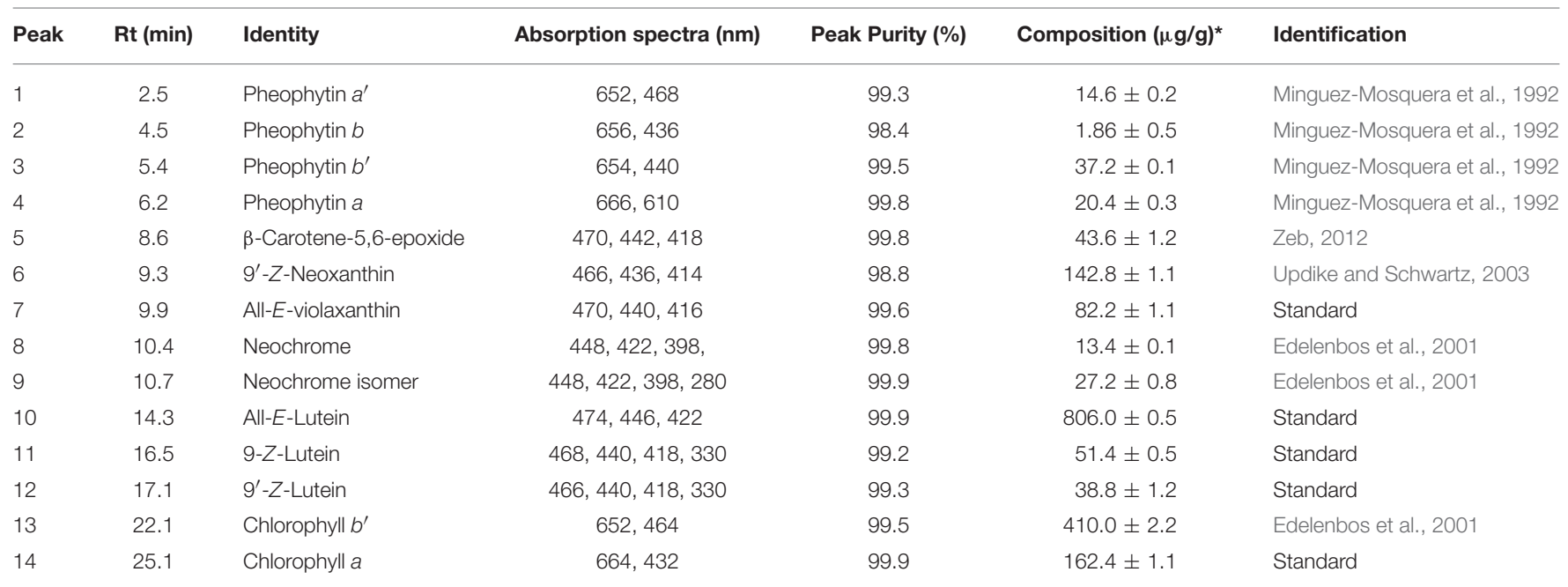

The compounds were identified by comparing absorption spectra of the sample with the available standards or from the absorption spectra reported in the literature.

*Values are expressed as mean \pm standard deviation (SD) of replicate readings based on fresh weight. 


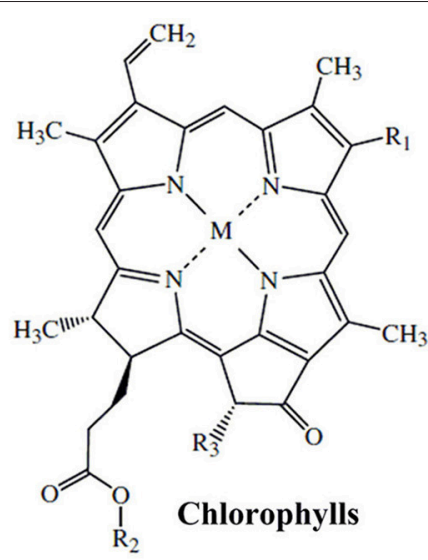

\begin{tabular}{lllll} 
Pigment & $\mathrm{M}$ & $\mathrm{R} 1$ & $\mathrm{R} 2$ & $\mathrm{R3}$ \\
\hline Chlorophyll a & $\mathrm{Mg}$ & $\mathrm{CH}_{2} \mathrm{CH}_{3}$ & $\mathrm{C}_{20} \mathrm{H}_{38}$ & $\mathrm{COOCH}_{3}$ \\
Chlorophyll b & $\mathrm{Mg}$ & $\mathrm{CHO}$ & $\mathrm{C}_{20} \mathrm{H}_{38}$ & $\mathrm{COOCH}_{3}$ \\
Pheophytin a & $2 \mathrm{H}$ & $\mathrm{CH}_{2} \mathrm{CH}_{3}$ & $\mathrm{C}_{20} \mathrm{H}_{38}$ & $\mathrm{COOCH}_{3}$ \\
Pheophytin b & $2 \mathrm{H}$ & $\mathrm{CHO}$ & $\mathrm{C}_{20} \mathrm{H}_{38}$ & $\mathrm{COOCH}_{3}$
\end{tabular}

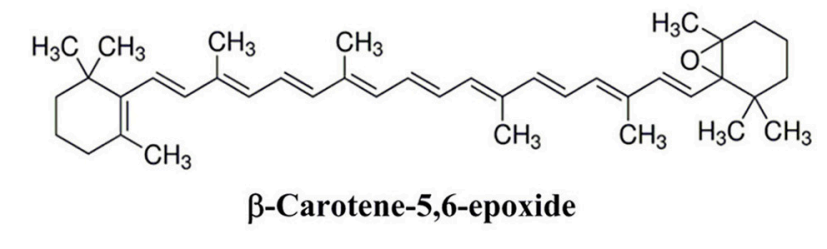

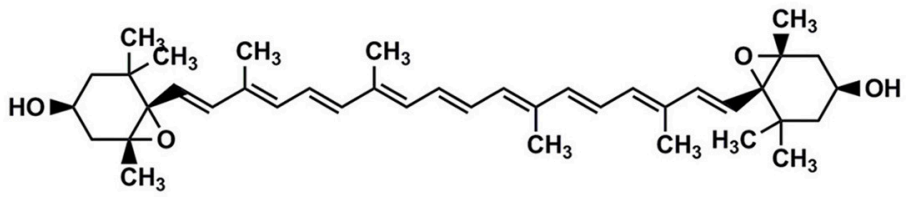

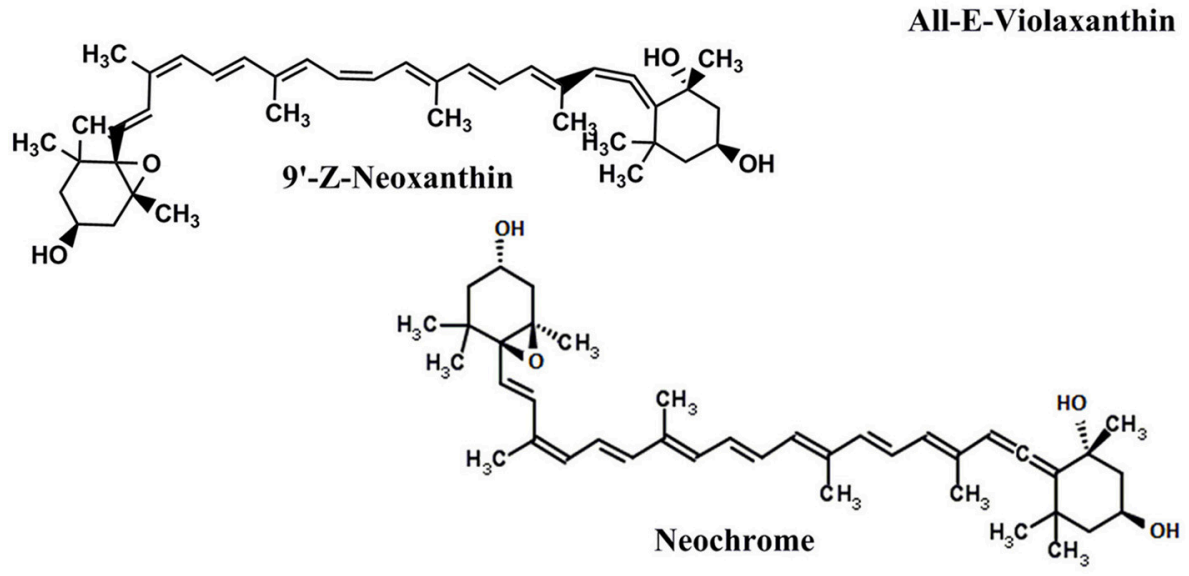<smiles>CCCC(O)CC</smiles><smiles>CC(C)=CC=CC(C)=CC=CC=C(C)C=CC=C(C)C=CC1C(C)=CC(O)CC1(C)C</smiles>

9'-Z-Lutein<smiles>CC(C)=CC(/C=C\C(C)=C/C=C/C(C)=C/C=C/C=C(C)/C=C/C=C(C)/C=C/C1=C(C)CC(O)CC1(C)C)C(C)(C)C</smiles>

FIGURE 2 | Chemical structures of the identified carotenoids and chlorophylls in Adiantum leaves. 


\section{RESULTS AND DISCUSSION}

\section{Carotenoids and Chlorophylls}

Figure 1 showed HPLC-DAD chromatograms of the carotenoids and the chlorophylls profile of the Adiantum leaves. Fourteen phenolic compounds were identified and quantified as described in details in Table 1 with structures as shown in the Figure 2. Compound 1 was eluted at 2.5 min and identified as pheophytin $a^{\prime}$ with absorption maxima of 652 and 458 with an amount of $14.6 \mu \mathrm{g} / \mathrm{g}$. This compound was identified from the work of Minguez-Mosquera et al. (1992). Compound 2 and 3 eluted at 4.5 and 5.4 min were pheophytin $b$ and $b^{\prime}$ with $\lambda \max$ of 656,436 and $654,440 \mathrm{~nm}$, respectively. The amount of compound 2 and 3 were 1.86 and $37.2 \mu \mathrm{g} / \mathrm{g}$, respectively. Compound 4 was pheophytin $a$ $(20.4 \mu \mathrm{g} / \mathrm{g})$ with $\lambda \max$ of 666 and $610 \mathrm{~nm}$ with retention time of $6.2 \mathrm{~min}$. All pheophytins were identified from the previously reported work (Minguez-Mosquera et al., 1992). Pheophytin $a$

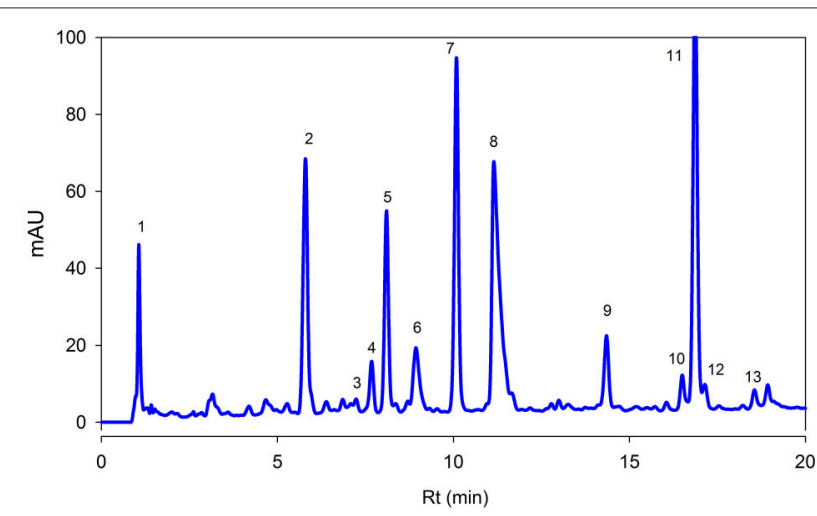

FIGURE 3 | Reversed phase HPLC-DAD profile of phenolic compounds present in the Adiantum leaves at $320 \mathrm{~nm}$. Each peak represents individual identified compounds with details given in Table 2. has anti-inflammatory properties by inhibiting nitric oxide via inducible nitric oxide synthase (Islam et al., 2013). $\beta$-Carotene5,6-epoxide was eluted at the retention time of $8.6 \mathrm{~min}$ with $\lambda \max$ of 470,442 , and $418 \mathrm{~nm}$. This compound was identified by comparing the absorption spectra from the reported previous work $(Z e b, 2012)$ with a concentration of $43.6 \mu \mathrm{g} / \mathrm{g}$. This epoxide is normally present in the chloroplasts, thylakoids, and other subchloroplast component of the leaves and upon digestion by the human, are well-absorbed (Barua and Olson, 2001).

Compound 6 was identified as $9^{\prime}-Z$-Neoxanthin with absorption maxima of 466, 436, $414 \mathrm{~nm}$ and eluted at $9.3 \mathrm{~min}$. This compound has composition of $142.8 \mu \mathrm{g} / \mathrm{g}$ and was identified from the work of Updike and Schwartz (2003). All$E$-violaxanthin was identified at retention time of $9.9 \mathrm{~min}$. This compound was identified from the standard compound with $\lambda \max$ of 470,440 , and 416 and a concentration of $82.2 \mu \mathrm{g} / \mathrm{g}$. All-E-violaxanthin is one of the precursor for the synthesis of neoxanthin (Strand et al., 2000). Compound 8 and 9 was identified as neochrome $(13.4 \mu \mathrm{g} / \mathrm{g})$ and its isomer, respectively. These compounds were identified by comparing the absorption spectra with reported literature (Edelenbos et al., 2001).

Lutein (compound 10) was present in the highest amounts $(806.0 \mu \mathrm{g} / \mathrm{g})$ has $\lambda \max$ of 474,446 , and $422 \mathrm{~nm}$. Lutein is a highly important pigment with antioxidant properties and is required for eye health and protection (Nwachukwu et al., 2016). Thus, the presence of a high amount of lutein in the Adiantum leaves will provide beneficial medicinal properties. Two $9-Z$ isomers of lutein i.e., 9-Z-lutein and $9^{\prime}$-Z-lutein were also identified as compound 11 and 12 with concentration of 51.4 and $38.8 \mu \mathrm{g} / \mathrm{g}$, respectively. These compounds were identified by comparing the absorption spectra with reported literature (Aman et al., 2005). Compound 13 was chlorophyll $b^{\prime}$ with $\lambda \max$ of 652 and 464 with retention time of $22.1 \mathrm{~min}$. This compound has second high concentration $(410.0 \mu \mathrm{g} / \mathrm{g})$ after lutein and was identified from the reported literature (Edelenbos et al., 2001).

TABLE 2 | Reversed phase HPLC-DAD profiling and quantification of bioactive phenolic compounds in Adiantum leaves.

\begin{tabular}{|c|c|c|c|c|c|c|}
\hline Peak & Rt (min) & Identity & $\begin{array}{l}\text { Absorption } \\
\text { spectra (nm) }\end{array}$ & Peak purity (\%) & Composition (mg/g)* & Identification reference \\
\hline 1 & 1.3 & 4-Hydroxybenzoic acid & 272 & 99.8 & $6.51 \pm 0.12$ & Standard \\
\hline 2 & 5.8 & 3-O-Caffeoylquinic acid & 326,298 & 99.4 & $28.5 \pm 0.23$ & Standard \\
\hline 3 & 7.2 & 2-Caffeoyl tartaric acid & 328,242 & 99.2 & $0.69 \pm 0.2$ & Standard \\
\hline 4 & 7.6 & Kaemferol-3-feruloylsophoroside-7-glucoside & 320,268 & 99.8 & $2.45 \pm 0.05$ & Santos et al., 2014 \\
\hline 5 & 8.1 & p-Coumaric acid & 312,232 & 99.4 & $11.2 \pm 0.15$ & Standard \\
\hline 6 & 8.9 & Rosmarinic acid & 326,288 & 98.9 & $24.4 \pm 0.07$ & Santos et al., 2014 \\
\hline 7 & 10 & Coumaric acid derivative & 307 & 99.6 & $33.1 \pm 0.06$ & Santos et al., 2014 \\
\hline 8 & 11.1 & 5-O-Caffeoylquinic acid & 332,283 & 99.8 & $18.7 \pm 0.01$ & Standard \\
\hline 9 & 14.3 & Quercetin hexoside derivatives & 356,255 & 99.0 & $2.54 \pm 0.02$ & Santos et al., 2014 \\
\hline 10 & 16.5 & Caffeic acid hexoside & 330,300 & 99.5 & $2.57 \pm 0.02$ & Santos et al., 2014 \\
\hline 11 & 16.8 & Kaempferol-3-O-sophorotrioside & 348,265 & 99.6 & $58.7 \pm 0.21$ & Santos et al., 2014 \\
\hline 12 & 17.1 & Quercetin rhamnoside-hexoside & 350,265 & 98.5 & $1.65 \pm 0.01$ & Santos et al., 2014 \\
\hline 13 & 18.5 & Quercetin-3-galactoside & 355,265 & 99.6 & $0.89 \pm 0.01$ & Santos et al., 2014 \\
\hline
\end{tabular}

The phenolic compounds were identified by comparing absorption spectra of the sample with the available standard compounds or from the absorption spectra reported in the literature. *Values are expressed as mean \pm standard deviation (SD) of replicate readings based on fresh weight. 
Similarly, chlorophyll $a$ was eluted at 25.1 min with $\lambda$ max of 664 and $432 \mathrm{~nm}$. Chlorophyll $a$ was identified and quantified from the standard compound and has received 3rd position on a quantitative basis with concentration of $162.4 \mu \mathrm{g} / \mathrm{g}$ after chlorophyll $b^{\prime}$. Chlorophyll $a$ is one of main pigment which has a link with light and soil moisture and consequently the growth performance in the Adiantum plant (Liao et al., 2013). These results indicate that Adiantum leaves were rich in carotenoids and chlorophylls pigments with significant biological properties.

\section{Phenolic Compounds}

Figure 3 showed separation of phenolic compounds in Adiantum leaves. Thirteen phenolic compounds were identified and quantified as shown in the Table 2 with structures as shown in Figure 4. The Peak 1 was identified as 4-hydroxbenzoic acid with $\lambda \max$ of $272 \mathrm{~nm}$ and concentration of $6.51 \mathrm{mg} / \mathrm{g}$. 4Hydroxybenzoic acid is one of the precursor for biosynthesis of phenolic compounds or as a degradation product. Peak 2 was identified as 3-O-caffeoylquinic acid (chlorogenic acid) with

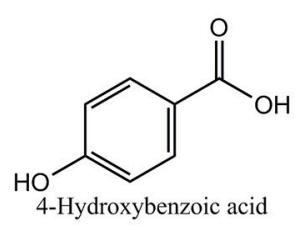<smiles>O=C(O)/C=C/c1ccc(O)cc1</smiles><smiles>COC1O[C@H](CO)[C@@H](O)[C@H](O)[C@H]1O</smiles><smiles>CC1CCC(O)CC1</smiles><smiles>[R20]/C=C(/O)C(O)Cc1ccc(O)c(O)c1</smiles>
Caffeic acid hexoside<smiles>CC(=O)O</smiles><smiles>CCC(C)O[C@H]1C[C@@](O)(C(=O)O)C[C@H](O)[C@H]1OC(=O)/C=C/c1ccc(O)c(O)c1</smiles><smiles>Cc1ccc(/C=C/C(=O)O[C@@H]2C[C@@](O)(C(=O)O)C[C@H](O)[C@H]2O)cc1O</smiles>

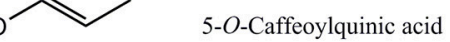
$\mathrm{HO}$<smiles>OCC(O)CO</smiles><smiles>OC[C@H]1OCC[C@@H](O)[C@@H]1O</smiles>

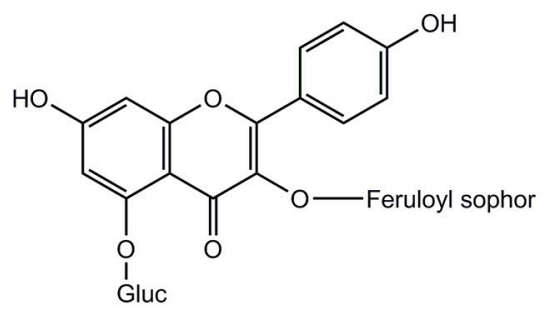

Kaempferol-3-ferologyl sophoroside-7-glucoside<smiles>C[C@H]1OC(Oc2c(-c3ccc(O)c(O)c3)oc3cc(O)cc(OC4OC(CO)C(O)C(O)C4O)c3c2=O)[C@H](O)[C@H](O)[C@@H]1O</smiles>

Quercetin rhamnoside-hexoside<smiles>C[C@H](O[C@H](O[C@@H]1O[C@H](CO)[C@@H](O)[C@H](O)[C@H]1O)[C@H](C)O)[C@@H](C)Oc1c(-c2ccc(O)cc2)oc2cc(O)cc(O)c2c1=O</smiles>

Kaempferol-3-O-sophorotrioside<smiles>O=c1c(OC2O[C@H](CO)[C@@H](O)[C@H](O)[C@H]2O)c(-c2ccc(O)c(O)c2)oc2cc(O)cc(O)c12</smiles>

Quercetin-3-galactoside

FIGURE 4 | Chemical structures of the identified phenolic compounds in Adiantum leaves. 
$\lambda \max$ of 326 and 298 sh and was eluted at the retention time of $5.8 \mathrm{~min}$. The amount of chlorogenic acid was $28.5 \mathrm{mg} / \mathrm{g}$ and was placed as third compound in terms of quantity. Chlorogenic acid is a strong antioxidant with several biological properties (Sato et al., 2011), especially helpful in inhibiting obesity by improving lipid metabolism (Cho et al., 2010). Chlorogenic acid was found to be highly stable under in-vitro gastrointestinal digestion system and highly bioavailable (Oliveira and Pintado, 2015; Mawalagedera et al., 2016). Therefore, biological engineering is required to produce plant with enhanced chlorogenic acid quantity (Niggeweg et al., 2004). The high amount of chlorogenic acid in the Adiantum may be responsible for the medicinal properties.

Caftaric acid (2-caffeoyl tartaric acid) was eluted as peak 3 with retention time of $7.2 \mathrm{~min}$ and $\lambda$ max of 328 and $242 \mathrm{~nm}$. Caftaric acid provide protection against the gastrointestinal inflammation (Sangiovanni et al., 2015). Peak 4 was tentatively identified as kaemferol-3-feruloylsophoroside-7-glucoside with characteristics $\lambda \max$ of 320 and $268 \mathrm{~nm}$ and was identified from the literature (Santos et al., 2014). Similarly, p-coumaric acid was identified using standard compound having a concentration of $11.2 \mathrm{mg} / \mathrm{g}$ and retention time of $7.1 \mathrm{~min}$ and its derivative was found to be the peak 7 with $\lambda$ max of $307 \mathrm{~nm}$ and relatively in similar amounts $(33.1 \mathrm{mg} / \mathrm{g})$. Coumaric acid was beneficial for improving or treating metabolic disorders especially modulating properties of glucose and lipid metabolism via AMP-activated protein kinase in skeletal muscles cells (Yoon et al., 2013). Coumaric acid or its metabolites have been found to be beneficial for treating lung cancer (Peng et al., 2015). Adiantum was rich in coumaric acid, may thus be a strong candidate for uses as medicinal or functional food. Peak 6 was tentatively identified as rosmarinic acid with characteristics $\lambda$ max of 326 and $288 \mathrm{~nm}$ and was eluted at 8.9 min. Rosmarinic acid demonstrated a strong potential for promoting beneficial antioxidant enzymes of the liver and kidneys (Zhang et al., 2015). Peak 8 was 5 -O-caffeoylquinic acid with retention time of $11.1 \mathrm{~min}$ was present in small amounts $(18.7 \mathrm{mg} / \mathrm{g})$. Peak 9, 12, and 13 were tentatively identified as quercetin hexose derivative, quercetin rhamnoside-hexoside and quercetin-3-galactoside, respectively. These derivatives were present in very small amounts as compared to other phenolic compounds. Peak 10 was tentatively identified as caffeoyl hexose with characteristics $\lambda$ max of 330 and $300 \mathrm{~nm}$ and retention time of $16.5 \mathrm{~min}$. Peak 11 was tentatively identified as kaempferol-3-sophorotrioside with highest concentration in the leaves $(58.7 \mathrm{mg} / \mathrm{g})$. This compound was eluted at $16.8 \mathrm{~min}$ with characteristics $\lambda \max$ of 348 and

\section{REFERENCES}

Ahmed, A., Wadud, A., Jahan, N., Bilal, A., and Hajera, S. (2013). Efficacy of Adiantum capillus veneris Linn in chemically induced urolithiasis in rats. J. Ethnopharmacol. 146, 411-416. doi: 10.1016/j.jep.2013.01.011

Al-Snafi, A. E. (2015). The chemical constituents and pharmacological effects of Adiantum capillus-veneris-A review. Asian J. Pharmaceut. Sci. Technol. 5, 106-111.
$265 \mathrm{~nm}$. Yuan et al. (2013) reported that Adiantum leaves contain kaempferol-3-glucosides in high amount. This suggests that kaempferol, or its glycosides can be considered as main finger printing compounds, which defines the medicinal properties of the plant. The uses of mass spectrometry could provide a better overlook to the derivative parts of phenolic acid and un-identified carotenoids, chlorophylls and phenolic compounds. From the results of the present work, it was concluded that Adiantum leaves were rich in nutritional and bioactive compounds, which can be used as a potential source of these compounds as food ingredients and in promoting or developing functional foods.

\section{CONCLUSIONS}

Adiantum leaves were collected and analyzed by HPLCDAD for carotenoids, chlorophylls and phenolic compound profiling. The leaves samples were extracted and separated using reversed phase HPLC with DAD. Results revealed eight carotenoids, four pheophytins, and two chlorophylls. Lutein, chlorophyll $a$, and $b^{\prime}$ and $9^{\prime}-Z$-neoxanthin were present in high amounts. The relatively high amount of lutein could be one of key indicator of beneficial antioxidant properties. The phenolic profile revealed a total of 13 compounds, namely 4hydroxybenzoic acid, chlorogenic acid, caftaric acid, kaempferol glycosides, p-coumaric acid, rosmarinic acid, 5-O-caffeoylquinic acid, and quercetin glycosides. Kaempferol-3-sophorotrioside, chlorogenic acid, coumaric acid, and its derivatives were present in high amounts. These results suggest that the reversed phase HPLC profiling of Adiantum leaves provides a good insight in to the actual composition of bioactive compounds responsible for important medicinal properties of this underutilized plant. Adiantum leaves were a good source of bioactive substances which can be used as a potential food ingredient or as a functional food.

\section{AUTHOR CONTRIBUTIONS}

AZ designed experiments, collected samples, interpreted the results and wrote the manuscript. FU performed extraction and analysis.

\section{FUNDING}

The authors are grateful for financial assistance of Higher Education Commission (HEC) Pakistan under NRPU project No. 2344.

Aman, R., Biehl, J., Carle, R., Conrad, J., Beifuss, U., and Schieber, A. (2005) Application of HPLC coupled with DAD, APCI-MS and NMR to the analysis of lutein and zeaxanthin stereoisomers in thermally processed vegetables. Food Chem. 92, 753-763. doi: 10.1016/j.foodchem.2004.10.031

Barua, A. B., and Olson, J. A. (2001). Xanthophyll epoxides, unlike $\beta$-carotene monoepoxides, are not detectibly absorbed by humans. J. Nutr. 131, 3212-3215.

Chiste, R. C., and Mercadante, A. Z. (2012). Identification and quantification, by HPLC-DAD-MS/MS, of carotenoids and phenolic compounds from the 
Amazonian fruit Caryocar villosum. J. Agric. Food Chem. 60, 5884-5892. doi: 10.1021/jf301904f

Cho, A.-S., Jeon, S.-M., Kim, M.-J., Yeo, J., Seo, K.-I., Choi, M.-S., et al. (2010). Chlorogenic acid exhibits anti-obesity property and improves lipid metabolism in high-fat diet-induced-obese mice. Food Chem. Toxicol. 48, 937-943. doi: 10.1016/j.fct.2010.01.003

Edelenbos, M., Christensen, L. P., and Grevsen, K. (2001). HPLC determination of chlorophyll and carotenoid pigments in processed green pea cultivars (Pisum sativum L.). J. Agric. Food Chem. 49, 4768-4774. doi: 10.1021/jf010569z

Haider, S., Nazreen, S., Alam, M. M., Gupta, A., Hamid, H., and Alam, M. S. (2011). Anti-inflammatory and anti-nociceptive activities of ethanolic extract and its various fractions from Adiantum capillus veneris Linn. J. Ethnopharmacol. 138, 741-747. doi: 10.1016/j.jep.2011.10.012

Hammond, B. R. Jr., and Fletcher, L. M. (2012). Influence of the dietary carotenoids lutein and zeaxanthin on visual performance: application to baseball. Am. J. Clin. Nutr. 96, 1207S-1213S. doi: 10.3945/ajen.112.034876

Hussain, F., Iqbal, I., and Durrani, M. J. (2006). Ethnobotany of Ghalegay, District Swat, Pakistan. Acta Bot. Yunn. 28, 305-314.

Ibraheim, Z. Z., Ahmed, A. S., and Gouda, Y. G. (2011). Phytochemical and biological studies of Adiantum capillus-veneris L. Saudi Pharm. J. 19, 65-74. doi: 10.1016/j.jsps.2011.01.007

Ishaq, M. S., Hussain, M. M., Afridi, M. S., Ali, G., Khattak, M., Ahmad, S., et al. (2014). In vitro phytochemical, antibacterial, and antifungal activities of leaf, stem, and root extracts of Adiantum capillus veneris. Sci. World J. 2014:269793. doi: $10.1155 / 2014 / 269793$

Islam, M. N., Ishita, I. J., Jin, S. E., Choi, R. J., Lee, C. M., Kim, Y. S., et al. (2013). Anti-inflammatory activity of edible brown alga Saccharina japonica and its constituents pheophorbide a and pheophytin a in LPSstimulated RAW 264.7 macrophage cells. Food Chem. Toxicol. 55, 541-548. doi: $10.1016 /$ j.fct.2013.01.054

Jiang, M.-Z., Yan, H., Wen, Y., and Li, X.-M. (2011). In vitro and in vivo studies of antioxidant activities of flavonoids from Adiantum capillus-veneris L. Afr. J. Pharm. Pharmacol. 5, 2079-2085. doi: 10.5897/AJPP11.500

Kimura, M., and Rodriguez-Amaya, D. B. (2002). A scheme for obtaining standards and HPLC quantification of leafy vegetable carotenoids. Food Chem. 78, 389-398. doi: 10.1016/S0308-8146(02)00203-0

Liao, J.-X., Jiang, M.-X., and Huang, H.-D. (2013). Growth characteristics of Adiantum reniforme var. sinensis and A. Capillus-veneris in response to light and soil moisture. Nordic J. Bot. 31, 500-504. doi: 10.1111/j.1756-1051. 2013.00192.x

Luterotti, S., and Kljak, K. (2010). Spectrophotometric estimation of total carotenoids in cereal grain products. Acta Chim. Slov. 57, 781-787.

Mawalagedera, S. M., Ou, Z.-Q., McDowell, A., and Gould, K. S. (2016). Effects of boiling and in vitro gastrointestinal digestion on the antioxidant activity of Sonchus oleraceus leaves. Food Funct. 7, 1515-1522. doi: 10.1039/C5FO 01508A

Minguez-Mosquera, M. I., Gandul-Rojas, B., and Gallardo-Guerrero, M. L. (1992). Rapid method of quantification of chlorophylls and carotenoids in virgin olive oil by high-performance liquid chromatography. J. Agric. Food Chem. 40, 60-63. doi: 10.1021/if00013a012

Niggeweg, R., Michael, A. J., and Martin, C. (2004). Engineering plants with increased levels of the antioxidant chlorogenic acid. Nat. Biotechnol. 22, 746-754. doi: 10.1038/nbt966

Nwachukwu, I. D., Udenigwe, C. C., and Aluko, R. E. (2016). Lutein and zeaxanthin: production technology, bioavailability, mechanisms of action, visual function, and health claim status. Trend Food Sci. Technol. 49, 74-84. doi: 10.1016/j.tifs.2015.12.005

Oliveira, A., and Pintado, M. (2015). Stability of polyphenols and carotenoids in strawberry and peach yoghurt throughout in vitro gastrointestinal digestion. Food Funct. 6, 1611-1619. doi: 10.1039/C5FO00198F

Peng, W., Wu, J.-G., Jiang, Y.-B., Liu, Y.-J., Sun, T., Wu, N., et al. (2015). Antitumor activity of 4-O-(2-O-acetyl-6-O-p-coumaroyl- $\beta$-d-glucopyranosyl)-pcoumaric acid against lung cancers via mitochondrial-mediated apoptosis. Chem. Biol. Interact. 233, 8-13. doi: 10.1016/j.cbi.2015.03.014
Reddy, V. L., Ravikanth, V., Rao, T. P., Diwan, P. V., and Venkateswarlu, Y. (2001). A new triterpenoid from the fern Adiantum lunulatum and evaluation of antibacterial activity. Phytochemistry 56, 173-175. doi: 10.1016/S0031-9422(00)00334-4

Reinaldo, R. C., Santiago, A. C., Medeiros, P. M., and Albuquerque, U. P. (2015). Do ferns and lycophytes function as medicinal plants? A study of their low representation in traditional pharmacopoeias. J. Ethnopharmacol. 175, 39-47. doi: 10.1016/j.jep.2015.09.003

Sangiovanni, E., Di Lorenzo, C., Colombo, E., Colombo, F., Fumagalli, M., Frigerio, G., et al. (2015). The effect of in vitro gastrointestinal digestion on the antiinflammatory activity of Vitis vinifera L. leaves. Food Funct. 6, 2453-2463. doi: 10.1039/C5FO00410A

Santos, J., Oliveira, M. B., Ibánez, E., and Herrero, M. (2014). Phenolic profile evolution of different ready-to-eat baby-leafvegetables during storage. J. Chromatogr. A 1327, 118-131. doi: 10.1016/j.chroma.2013.12.085

Sato, Y., Itagaki, S., Kurokawa, T., Ogura, J., Kobayashi, M., Hirano, T., et al. (2011). In vitro and in vivo antioxidant properties of chlorogenic acid and caffeic acid. Int. J. Pharm. 403, 136-138. doi: 10.1016/j.ijpharm.2010.09.035

Singh, M., Singh, N., Khare, P. B., and Rawat, A. K. (2008). Antimicrobial activity of some important Adiantum species used traditionally in indigenous systems of medicine. J. Ethnopharmacol. 115, 327-329. doi: 10.1016/j.jep.2007.09.018

Soares Nda, C., Teodoro, A. J., Lotsch, P. F., Granjeiro, J. M., and Borojevic, R. (2015). Anticancer properties of carotenoids in prostate cancer. A review. Histol. Histopathol. 30, 1143-1154. doi: 10.14670/HH-11-635

Strand, A., Kvernberg, K. M., Karlsen, A., and Liaaen-Jensen, S. (2000). Geometrical E/Z isomers of (6R)- and (6S)-neoxanthin and biological implications. Biochem. System. Ecol. 28, 443-455. doi: 10.1016/S0305-1978 (99)00078-2

Updike, A. A., and Schwartz, S. J. (2003). Thermal processing of vegetables increases cis isomers of lutein and zeaxanthin. J. Agric. Food Chem. 51, 6184-6190. doi: 10.1021/jf030350f

Yoon, S.-A., Kang, S.-I., Shin, H.-S., Kang, S.-W., Kim, J.-H., Ko, H.-C., et al. (2013). p-Coumaric acid modulates glucose and lipid metabolism via AMPactivated protein kinase in L6 skeletal muscle cells. Biochem. Biophys. Res. Commun. 432, 553-557. doi: 10.1016/j.bbrc.2013.02.067

Yuan, Q., Wang, J., and Ruan, J. (2012). Screening for bioactive compounds from Adiantum capillus-veneris L. J. Chem. Soc. Pak. 34, 207-216.

Yuan, Q., Zhang, X., Liu, Z., Song, S., Xue, P., Wang, J., et al. (2013). Ethanol extract of Adiantum capillus-veneris L. suppresses the production of inflammatory mediators by inhibiting NF-kappa B activation. J. Ethnopharmacol. 147, 603-611. doi: 10.1016/j.jep.2013.03.046

Zeb, A. (2012). Oxidation and formation of oxidation products of $\beta$-carotene at boiling temperature. Chem. Phys. Lipids 165, 277-281. doi: 10.1016/ j.chemphyslip.2012.02.005

Zeb, A. (2015). A reversed phase HPLC-DAD method for the determination of phenolic compounds in plant leaves. Anal. Methods 7, 7753-7757. doi: 10.1039/C5AY01402F

Zeb, A. (2017). A simple, sensitive HPLC-DAD method for simultaneous determination of carotenoids, chlorophylls and $\alpha$-tocopherol leafy vegetables. J. Food Meas. Charact. doi: 10.1007/s11694-017-9472-y. [Epub ahead of print].

Zhang, Y., Chen, X., Yang, L., Zu, Y., and Lu, Q. (2015). Effects of rosmarinic acid on liver and kidney antioxidant enzymes, lipid peroxidation and tissue ultrastructure in aging mice. Food Funct. 6, 927-931. doi: 10.1039/C4FO01051E

Conflict of Interest Statement: The authors declare that the research was conducted in the absence of any commercial or financial relationships that could be construed as a potential conflict of interest.

Copyright (C) 2017 Zeb and Ullah. This is an open-access article distributed under the terms of the Creative Commons Attribution License (CC BY). The use, distribution or reproduction in other forums is permitted, provided the original author(s) or licensor are credited and that the original publication in this journal is cited, in accordance with accepted academic practice. No use, distribution or reproduction is permitted which does not comply with these terms. 